\author{
Yang Sun \\ The Affiliated Hospital of Qingdao University \\ Yanjun Guo \\ The Affiliated Hospital of Qingdao University \\ Yaqing Wu \\ Jiangsu Simcere Diagnostics Co., Ltd \\ Ningning Luo \\ Jiangsu Simcere Diagnostics Co., Ltd \\ Xinjia He ( $\nabla$ hxi13608970051@163.com ) \\ The Affiliated Hospital of Qingdao University
}

$\$$ Research Square

Preprints are preliminary reports that have not undergone peer review. They should not be considered conclusive, used to inform clinical practice, or referenced by the media as validated information.

\section{Guillain-Barre Syndrome Caused by Tislelizumab and Axitinib}

\section{Research Article}

Keywords: Advanced renal cell carcinoma, Immunotherapy, Guillain-Barré syndrome, Tislelizumab, Axitinib

Posted Date: June 14th, 2021

DOI: https://doi.org/10.21203/rs.3.rs-564774/v1

License: (c) (i) This work is licensed under a Creative Commons Attribution 4.0 International License. Read Full License 


\section{Abstract}

Immunotherapy combinations have changed the treatment paradigm of advanced renal cell carcinoma (RCC). Notably, immunotherapy induces a new spectrum of immune-related adverse events (irAEs). Guillain-Barré syndrome (GBS) is a rare and potentially fatal nervous system irAE. The activation of T-cell is considered a triggering factor of GBS. We herein reported a case of GBS-like syndrome during treatment of tislelizumab and axitinib in a patient with RCC. To our knowledge, this is the first report of tislelizumab-related GBS.

\section{Introduction}

Immune checkpoint inhibitors $(\mathrm{ICl})$ and its combination with anti-angiogenic inhibitors are now a standard treatment for advanced RCC ${ }^{[1]}$. With the increased use of $\mathrm{ICl}$, clinicians should be aware of the possible risks of irAEs. Tislelizumab is a fully humanized IgG4 antibody against programmed cell death 1 (PD1) receptor. Different with the other anti-PD1 agents(eg Nivolumab, Pembrolizumab), tislelizumab has been gene-engineered to reduce its affinity for the Fc receptor $^{[2]}$. Currently, 57 clinical trials, including RCC, have been registered in ClinicalTrials.gov. Here, we first describe a male RCC patient who developed neurological symptoms induced by tislelizumab.

\section{Case Presentation}

A 65-year-old man with 20-year history of hypertension and 5-year history of diabetes was admitted to Peking University First Hospital due to a spaceoccupying lesion in the left kidney. PET-CT (positron emission tomography-computed tomography) showed a left renal mass, a thyroid nodule and an inflammatory lesion in lung. The bone density of left femur, right acetabulum, sacral vertebrae and T7 spinous process increased. Surgical resection was performed in Dec 2019. RCC with sarcomatoid and rhabdoid differentiation was confirmed by pathology. Pathology also found metastatic tumor in the left adrenal gland. Adjuvant targeted therapy with sorafenib (400 mg) was administered in Jan 2020. In Mar 2020, he underwent surgical resection for the thyroid nodule. CT reexamination revealed bone destruction of the left 9th rib and T7 vertebra in Sep 2020, so the patient was transferred to our hospital for further treatment. Sorafenib treatment was then replaced by denosumab $(120 \mathrm{mg})$ combination with tislelizumab(200 mg) and axitinib (5 mg). 13 days after the third cycles of tislelizumab, the patient developed dysphagia, generalized weakness, blepharoptosis and aberrant eye movements.

Laboratory examination results revealed increased creatine kinase (2110, normal 59-248; Dec 23, 2020; Day0). No evidence of infection was found. Magnetic resonance imaging of the brain and spinal cord were normal. Physical and neurological examination revealed a decrease in muscle strength of the limbs. Nerve electrophysiological tests on Day11 revealed extensive neurogenic damage, reduced motor nerve wave amplitudes and prolonged $\mathrm{F}$ wave latencies(Table 1-2).

He received methylprednisolone sodium succinate treatment $(80 \mathrm{mg})$ immediately on Day1. Four days later, treatment was switched to methylprednisolone (40 mg) along with $60 \mathrm{mg}$ methylprednisolone sodium succinate. On Day8, the doctors weaned methylprednisolone sodium succinate dose to 40 mg and terminated it on Day11. Methylprednisolone treatment was continued. After 21 days glucocorticosteroid treatment, the patient's muscular strength and speech improved, but he still suffered form choking cough after drinking, so neurological consultation was sought (Day22). The patient refused to perform cerebrospinal fluid (CSF) analysis. Treatment effects of sorafenib or denosumab was excluded after communication with manufacturers. Taken all results together, he was diagnosed with GBS-like syndrome. He then received intravenous immunoglobulin (IVIG) 400mg/kg/day for 5 days. On Day28, IVIG was terminated because his symptoms further improved. Methylprednisolone treatment was continued (Day65) along with axitinib (Day24-Day58). Unfortunately, the patient got a high fever on Day58. COVID-19 test was negative (real-time Polymerase Chain Reaction). He developed severe pneumonia and died of bacterial lung infections on Day66.

\section{Discussion}

A review of the literature showed that the incidence of neurological adverse events (nAEs) was $3.8 \%$ with anti-CTLA4 inhibitors, $6.1 \%$ with anti-PD1 inhibitors, and $12.0 \%$ with the combination of anti-CTLA4 + anti-PD1 inhibitors ${ }^{[3]}$. Another review of 7604 patients treated with immune checkpoint inhibitors (ICI) revealed a $7.7 \%$ overall incidence of $\mathrm{nAEs}$ and $0.1 \%$ incidence of GBS/MFS (Miller-Fisher syndrome) ${ }^{[4]}$. GBS is an acute autoimmune disorder affecting peripheral nervous system. T cell mediated immunity is considered as a trigger factor of GBS, and antibodies and complement are thought to be involved in the process. In addition, ganglioside antibodies that target macrophages are thought to play a crucial role ${ }^{[5]}$.

Anti-PD1 agents were initially developed for blocking the PD1/PDL1 (programmed death-ligand 1) signaling pathway, which was confirmed to be involved in tumor immune escape. However, PD1 also expressed on activated B cells, natural killer cells and regulatory T cells (Tregs) ${ }^{[6]}$. Combination with anti-VEGF drugs does promote anti-tumor response, but it may trigger more complex autoimmunity. Macrophages-mediated ADCP (antibody-dependent cellular phagocytosis) can cause depletion of target cell. Fc region of tislelizumab is genetically engineered to lower affinity for Fc receptor on macrophages, which is different from nivolumab or pembrolizumab ${ }^{[2]}$. Currently, tislelizumab is approved by the National Medical Products Administration (NMPA, formerly the China Food and Drug Administration) for the treatment of classical Hodgkin Lymphomas, Urothelium Carcinoma and Lung Squamous Cell Carcinoma. So far, tislelizumab-related GBS has not been reported.

Due to the complicated action mechanism of ICl, it is difficult to elucidate the causes of ICI-related GBS. Fortunately, there has been a proposed diagnostic and treatment paradigm for ICI high-grade neurological complications ${ }^{[7]}$. CSF and EMG analysis are critical diagnostics steps. IVIG (intravenous immunoglobulin), plasmapheresis and glucocorticoid treament are effective therapies for ICI-related GBS ${ }^{\text {[7-22] }}$. 
16 ICl-related GBS patients (15 publications) were found via PubMed with median age 63 years (range: $45-81$ years) ${ }^{[8-22]}$, including 1 bladder, 1 nasal, 1 kidney, 5 lung and 8 melanoma cancer patients. Male patients accounted for 75\%. Prognosis of these cases varies, 5 patients were confirmed dead (age range: $63-81$ years) ${ }^{[9-10,12,19,21]}$. Patient in our case refused CSF analysis, so he was diagnosed with GBS-like syndrome. Glucocorticoid and IVIG treament improved clinical symptoms. However, he developed severe pneumonia during treatment and died after 3 days ICU admission. Additionally, CT on Day58 showed disease progression of lung and bone.

In summary, we reported the first GBS-like syndrome case related with tislelizumab. Rapid diagnosis and treatment of GBS are crucial because irAEs can initiate serious sequelae or death. A multidisciplinary approach is necessary for patients who received immunotherapies.

Table 1. Nerve electrophysiological tests results part1

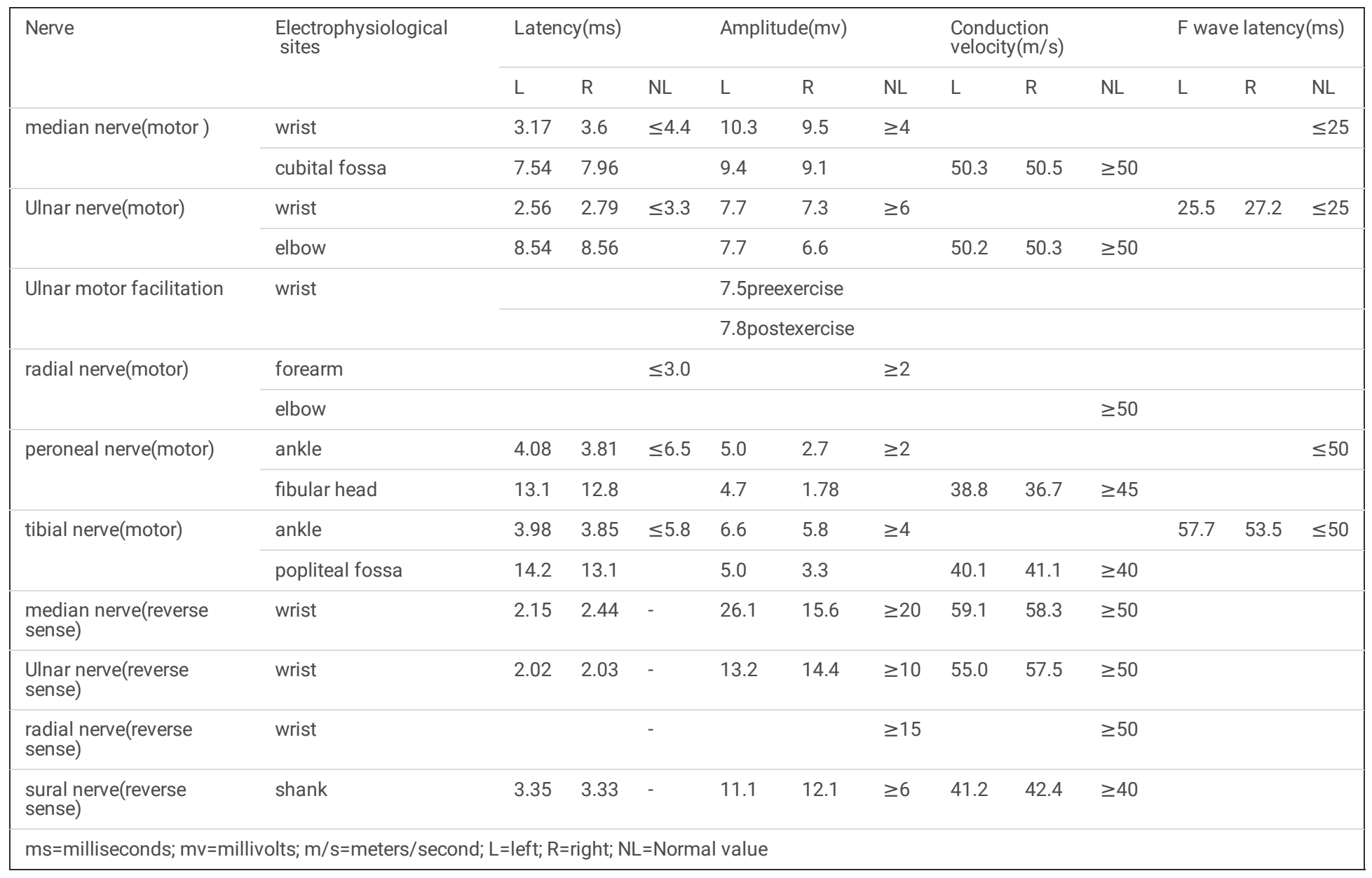

Table 2. Nerve electrophysiological tests results part2 


\begin{tabular}{|c|c|c|c|c|c|c|c|c|c|c|c|}
\hline \multirow[t]{2}{*}{ L/R } & \multirow[t]{2}{*}{ Muscle } & \multirow[t]{2}{*}{ Innervation } & \multirow{2}{*}{$\begin{array}{l}\text { Insertion } \\
\text { potential }\end{array}$} & \multicolumn{4}{|c|}{ Spontaneous potential } & \multicolumn{4}{|c|}{ Voluntary MUP } \\
\hline & & & & fibrillation & $\begin{array}{l}\text { positive } \\
\text { sharp }\end{array}$ & fasciculation & other & $\begin{array}{l}\text { time } \\
\text { limit( }(\uparrow \downarrow \%)\end{array}$ & amplitude & $\begin{array}{l}\text { polyphase } \\
\text { wave }\end{array}$ & recruitment \\
\hline L & trapezius & accessory & NL & ( & ? & प & ( & NL & NL & NL & NL \\
\hline $\mathrm{R}$ & biceps brachii & $\begin{array}{l}\text { C5/6, } \\
\text { musculo }\end{array}$ & NL & प & ( & प & ? & NL & NL & NL & NL \\
\hline $\mathrm{R}$ & $\begin{array}{l}\text { first } \\
\text { interosseous } \\
\text { muscle }\end{array}$ & $\begin{array}{l}\text { C8/T1, } \\
\text { ulnar }\end{array}$ & NL & ( & ? & ( & ? & NL & NL & NL & NL \\
\hline $\mathrm{L}$ & $\begin{array}{l}\text { first } \\
\text { interosseous } \\
\text { muscle }\end{array}$ & & NL & 口 & ] & — & ] & NL & NL & NL & NL \\
\hline L & $\begin{array}{l}\text { vastus } \\
\text { medialis }\end{array}$ & $\begin{array}{l}\text { L3/4, } \\
\text { femoral }\end{array}$ & NL & ( & ( & - & - & NL & NL & NL & NL \\
\hline L & $\begin{array}{l}\text { tibialis anterior } \\
\text { muscle }\end{array}$ & $\begin{array}{l}\mathrm{L} 4 / 5 \text {, } \\
\text { peroneal }\end{array}$ & NL & प & प & - & - & NL & NL & NL & NL \\
\hline L & gastrocnemius & $\mathrm{S} 1 / 2$, tibial & NL & प & ( & प & ] & NL & NL & NL & NL \\
\hline $\mathrm{R}$ & $\begin{array}{l}\text { tibialis anterior } \\
\text { muscle }\end{array}$ & $\begin{array}{l}\text { L4/5, } \\
\text { peroneal }\end{array}$ & NL & $2 \rrbracket$ & $2 \rrbracket$ & ૫ & ( & NL & NL & NL & NL \\
\hline $\mathrm{R}$ & gastrocnemius & & NL & 口 & ] & 口 & 口 & NL & NL & NL & NL \\
\hline $\mathrm{R}$ & $\begin{array}{l}\text { vastus } \\
\text { medialis }\end{array}$ & & NL & Q & ? & प & ? & NL & NL & NL & NL \\
\hline L & $\begin{array}{l}\text { paravertebral } \\
\text { muscle }\end{array}$ & T9 & NL & $2 \rrbracket$ & $2 \rrbracket$ & प & ( & NL & NL & NL & NL \\
\hline
\end{tabular}

\section{Declarations}

Funding The authors did not receive any funding for this study.

Availability of data and material Not applicable.

Code availability Not applicable.

Authors' contributions YS, YG: contributed to the conception of the study. YW, NL: performed the data analyses and wrote the manuscript. XH: helped perform the analysis with constructive discussions.

Ethical approval The research was approved by the Institutional Ethics Review Board of The Affiliated Hospital of Qingdao University.

Compliance with ethical standards

Disclosure of potential conflicts of interest All authors have no conflicts of interest to disclose.

Research involving Human Participants and/or Animals This study does not contain any studies with human participants or animals performed by any of the authors.

Informed consent Informed consent was obtained from the patient for the publication of this case report.

Consent to participate The patient and the family consent to participate.

Consent for publication A written informed consent was obtained from the patient for publication.

Acknowledgements The authors thank Ms. Tingting Sun and Mr. Chuang Qi, Mr. Wanglong Deng, Mr. Guanghua Lu, and Mr. Ran Ding from Simceredx for the kindly assistance.

\section{References}

1. Díaz-Montero CM, Rini BI, Finke JH (2020) The immunology of renal cell carcinoma. Nat Rev Nephrol 16: 721-735. https://doi.org/10.1038/s41581-0200316-3

2. Zhang T, Song X, Xu L, Ma J, Zhang Y, Gong W, Zhang Y, Zhou X, Wang Z, Wang Y, Shi Y, Bai H, Liu N, Yang X, Cui X, Cao Y, Liu Q, Song J, Li Y, Tang Z, Guo M, Wang L, Li K (2018) The binding of an anti-PD-1 antibody to FcyRI has a profound impact on its biological functions. Cancer Immunol Immunother 67 : 1079-1090. https://doi.org/10.1007/s00262-018-2160-x 
3. Cuzzubbo S, Javeri F, Tissier M, Roumi A, Barlog C, Doridam J, Lebbe C, Belin C, Ursu R, Carpentier AF (2017) Neurological adverse events associated with immune checkpoint inhibitors: Review of the literature. Eur J Cancer 73: 1-8. https://doi.org/10.1016/j.ejca.2016.12.001

4. Sato K, Mano T, Iwata A, Toda T (2019) Neurological and related adverse events in immune checkpoint inhibitors: a pharmacovigilance study from the Japanese Adverse Drug Event Report database. J Neurooncol 145: 1-9. https://doi.org/10.1007/s11060-019-03273-1

5. Hughes RAC, Cornblath DR (2005) Guillain-Barré syndrome. Lancet 366: 1653-1666. https://doi.org/10.1016/S0140-6736(05)67665-9

6. Francisco LM, Salinas VH, Brown KE, Vanguri VK, Freeman GJ, Kuchroo VK, Sharpe AH (2009) PD-L1 regulates the development, maintenance, and function of induced regulatory T cells. J Exp Med 206: 3015-3029. https://doi.org/10.1084/jem.20090847

7. Anderson D, Beecher G, Nathoo N, Smylie M, McCombe JA, Walker J, Jassal R (2019) Proposed diagnostic and treatment paradigm for high-grade neurological complications of immune checkpoint inhibitors. Neurooncol Pract 6: 340-345. https://doi.org/10.1093/nop/npy039

8. Wilgenhof S, Neyns B (2011) Anti-CTLA-4 antibodyinduced Guillain-Barre syndrome in a melanoma patient. Ann Oncol 22: $991-993$. https://doi.org/10.1093/annonc/mdr028

9. Bot I, Blank CU, Boogerd W, Brandsma D (2013) Neurological immune-related adverse events of ipilimumab. Pract Neurol 13: $278-280$. https://doi.org/10.1136/practneurol-2012-000447

10. Gaudy-Marqueste C, Monestier S, Franques J, Cantais E, Richard MA, Grob JJ (2013) A severe case of ipilimumab-induced guillain-barré syndrome revealed by an occlusive enteric neuropathy: a differential diagnosis for ipilimumab-induced colitis. J Immunother 36: 77-78. https://doi.org/10.1097/CJI.0b013e31827807dd

11. de Maleissye MF, Nicolas G, Saiag P (2016) Pembrolizumab-induced demyelinating polyradiculoneuropathy. N Engl J Med 375: $296-297$. https://doi.org/10.1056/NEJMc1515584

12. Jacob A, Unnikrishnan DC, Mathew A, Thyagarajan B, Patel S (2016) A case of fatal Guillain-Barre syndrome from anti-PD1 monoclonal antibody use. J Cancer Res Clin Oncol 142: 1869-1870. https://doi.org/10.1007/s00432-016-2191-7

13. Gu Y, Menzies AM, Long GV, Fernando SL, Herkes G (2017) Immune mediated neuropathy following checkpoint immunotherapy. J Clin Neurosci 45: $14-17$. https://doi.org/10.1016/j.jocn.2017.07.014

14. Schneiderbauer R, Schneiderbauer M, Wick W, Enk AH, Haenssle HA, Hassel JC (2017) PD-1 antibody-induced guillain-barre syndrome in a patient with metastatic melanoma. Acta Derm Venereol 97: 395-396. https://doi.org/10.2340/00015555-2548

15. Supakornnumporn S, Katirji B (2017) Guillain-barre syndrome triggered by immune checkpoint inhibitors: A case report and literature review. J Clin Neuromuscul Dis 19: 80-83. https://doi.org/10.1097/CND.0000000000000193

16. Nukui T, Nakayama Y, Yamamoto M, Taguchi Y, Dougu N, Konishi H, Hayashi T, Nakatsuji Y (2018) Nivolumab-induced acute demyelinating polyradiculoneuropathy mimicking Guillain-Barre syndrome. J Neurol Sci 390: 115-116. https://doi.org/10.1016/j.jns.2018.04.028

17. Fukumoto Y, Kuwahara M, Kawai S, Nakahama K, Kusunoki S (2018) Acute demyelinating polyneuropathy induced by nivolumab. J Neurol Neurosurg Psychiatry 89: 435-437. https://doi.org/10.1136/jnnp-2017-316510

18. Thapa B, Khalid S, Vakili R, Ui J, Misbah S (2018) Nivolumab-associated Guillain-barre syndrome in a patient with non-small-cell lung cancer. Am J Ther 25: 761-763. https://doi.org/10.1097/MJT.0000000000000771

19. Manam R, Martin JL, Gross JA, Chaudhary D, Chowdhary S, Espinosa PS, Santos ES (2018) Case reports of pembrolizumab-induced acute inf lammatory demyelinating polyneuropathy. Cureus 10: 3371. https://doi.org/10.7759/cureus.3371

20. Ong S, Chapman J, Young G, Mansy T (2018) Guillain-Barre-like syndrome during pembrolizumab treatment. Muscle Nerve. https://doi.org/10.1002/mus.26101. Online ahead of print.

21. Kyriazoglou A, Liontos M, Papadopoulos C, Bilali A, Kostouros E, Pagoni S, Doumas K, Dimopoulos MA, Bamias A (2019) Guillain-barre syndrome related to nivolumab: Case report of a patient with urothelial cancer and review of the literature. Clin Genitourin Cancer 17: 360-364. https://doi.org/10.1016/j.clgc.2018.11.022

22. Han C, Ma JA, Zhang Y, Jiang Y, Hu C, Wu Y (2020) Guillain-Barre syndrome induced by pembrolizumab and sunitinib: A case report. Mol Clin Oncol 13: 38-42. https://doi.org/10.3892/mco.2020.2042 